\title{
FACTORS AFFECTING THE SUCCESS RATE OF EXTERNAL DACRYOCYSTORHINOSTOMY AT B. P. KOIRALA INSTITUTE OF HEALTH SCIENCES, DHARAN, NEPAL
}

\author{
Pokharel $S M^{1 *}$, Chaudhary $S K^{1}$, Chaurasiya $B D^{2}$
}

\section{Affiliation}

1. Assistant Professor, Department of Ophthalmology, B. P. Koirala Institute Health Science.

2. Junior Resident, Department of Opthamology, B. P. Koirala Institute Health Science.

\section{A R T I CLE INFO}

\section{Article History}

Received : 30 May, 2017

Accepted : 23 July, 2017

Published : 30 August, 2017

(C) Authors retain copyright and grant the journal right of first publication with the work simultaneously licensed under Creative Commons Attribution License CC - BY 4.0 that allows others to share the work with an acknowledgment of the work's authorship and initial publication in this journal.

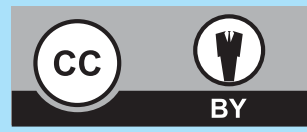

ORA 30

\section{* Corresponding Author \\ Dr. Shailesh Mani Pokharel Assistant Professor \\ Department of Ophthalmology}

B. P. Koirala Institute of Health Sciences, Dharan, Nepal Email: shailesh.pokharel@bpkihs.edu

\section{Citation}

Pokharel SM, Chaudhary SK, Chaurasiya BD. Factors Affecting the Success Rate of External Dacryocystorhinostomy at B. P. Koirala Institute of Health Sciences, Dharan, Nepal. BJHS 2017;2 (2)3:196-200.

\section{ABSTRACT}

\section{Introduction}

Any disturbance to the normal outflow of tears through the nasolacrimal passage causes overflow known as epiphora. The clinical symptoms of epiphora range from mild dribble to the continuous outflow of tears. Watering of eyes caused by the nasolacrimal drainage obstruction is managed by surgery. One of the many surgeries to treat this is external dacryocystorhinostomy.

\section{Objective}

The objective of this study was to evaluate the success rate of external dacryocystorhinostomy as well as factors affecting it.

\section{Methodology}

This is a retrospective cross-sectional study, conducted in the Department of Ophthalmology, B. P. Koirala Institute of Health Sciences (BPKIHS), Dharan with the approval of Institutional Review Committee, BPKIHS. The medical records of patients who underwent external Dacryocystorhinostomy surgery from April 2011 to April 2016 at BPKIHS were retrospectively reviewed. Statistical analysis was performed using SPSS for windows, version 11.5 (SPSS Inc., Chicago, IL). Binary logistic regression models were used to investigate the association of the surgical outcome with various predicting variables.

\section{Results}

The success rate of the external dacryocystorhinostomy was $78.09 \%$. Factors studied were: age, with a range of 2-81 years; duration of symptoms with a range of 1-84 months; and gender of the patients. The intra-operative factors studied were use of silastic tube, types of flap, and osteotomy size. Among these factors, the duration of symptoms and osteotomy size had significant association with the outcome of the surgery $p<0.05$.

\section{Conclusion}

Our study yielded high success rate in patients with shorter duration of watering of eyes and larger osteotomy size during surgery. Hence, a larger osteotomy size and early intervention is recommended for better surgical outcome.

\section{KEY WORDS}

Epiphora, external dacryocystorhinostomy, nasolacrimal duct obstruction 


\section{INTRODUCTION}

Normal flow of tears from the eye to the nose is through the nasolacrimal passage. Any disturbance to the normal outflow causes overflow of tears known as epiphora. Nasolacrimal duct obstruction is successfully managed by a procedure known as external Dacryocystorhinosotmy (DCR). External DCR Technique introduced by Toti was later modified with suturing of the anterior and posterior lacrimal and nasal flaps by Dutemps and Bourget in $1921{ }^{1}$

External dacryocystorhinosotmy (DCR) till today remains the gold standard technique for the management of nasolacrimal duct obstruction. Since 1980, another technique of DCR surgery, Endoscopic endolaser DCR has been popularized as an alternative option for the conventional external DCR surgery. ${ }^{2,3,4,5}$ Endolaser assisted DCR surgery was introduced by Massaro et al in 1990. ${ }^{6}$ Other techniques of DCR surgeries are transcanalicular laser dacryocystorhinostomy, ${ }^{7}$ conjunctiv odacryocy storhinostomy. ${ }^{8}$

Definition for success of DCR surgery is different in various studies. Some author have defined success based on the patency of the drainage system along with the lack of symptoms and others have divided success rate into objective that is anatomic success, subjective that is functional success and lastly, anatomic which is success with partial relief of symptoms.,

Various factors affecting the success rate of external dacryocystorhinostomy are duration of watering of the eye, age, sex, past history of external DCR, size of bony osteotome, closure of both the anterior and posterior mucosal flap with lacrimal sac flap, use of silicone tube intubation. ${ }^{10}$

External Dacryocystorhinostomy surgery (DCR) continues to be a gold standard surgery for nasolacrimal duct obstruction. ${ }^{11}$ External dacryocystorhinostomy yields higher success rates which is more than $90 \%$ as reported in literature. ${ }^{12,13}$ The use bicanalicular silicone tube intubation while performing external DCR surgery is optional for the surgeons. ${ }^{10}$ This study was conducted to evaluate success rate and the factors affecting a successful external dacryocystorhinostomy.

\section{METHODOLOGY}

This is a retrospective cross sectional study, conducted in the Department of Ophthalmology, B. P. Koirala Institute of Health Sciences, Dharan with the approval of Institutional Review Committee, BPKIHS. The medical records of the patients those who underwent external Dacryocystorhinostomy surgery from April 2011 to April 2016 at B P Koirala Institute of Health Sciences were retrospectively reviewed. The patients included in the study were with the diagnosis of nasolacrimal duct obstruction based on the history of watering of the eyes and the presence of regurgitation of fluid or mucopurulent discharge on pressure over the lacrimal sac (ROPLAS) and reflux of fluid on syringing of the lacrimal passage. Patient with rhinosporodiosis of the lacrimal drainage system, encysted mucocele and canalicular block were excluded. A detailed medical record of one hundred and five patients who underwent external dacryocystorhinostomy during the above mention duration was obtained.

A clinical history regarding age, sex, duration of disease, past history of the dacryocystorhinostomy and ocular examination including visual acuity, examination of both the anterior segment and posterior segment, syringing, probing as well as ROPLAS test was assessed from medical records.

After confirming the diagnosis of nasolacrimal duct obstruction, blood hemoglobin level, bleeding time and clotting time were measured. Patients who were less than 15 years old were planned for ext-DCR surgery under general anesthesia, whereas other patients were under local anesthesia.

The patients were examined on the first post-operative day. Assessment was based on symptoms, regurgitation on pressure over lacrimal sac region (ROPLAS) test and check for reflux of fluid in syringing test. Patient without symptoms along with patent lacrimal passages were considered to have had successful external DCR surgery.

\section{Surgical Technique}

A standard ext-DCR procedure was performed in all cases. The nasal cavity of the operative side was packed with gauze soaked in $2 \%$ xylocaine containing adrenaline 1:200,000 I.U., and $2 \%$ xylocaine with 1:200,000 adrenaline was injected subcutaneously in the medial canthal area. Skin of 10-14 mm size was then incised with a \#15 Bard-Parker blade and blunt dissection of the muscle was performed until the periosteum of the frontal process of the maxilla was identified. Desmarre's retractor traction was applied to prevent haemorrhage from the muscle. A periosteal elevator was used to elevate the periosteum over the anterior lacrimal crest and into the lacrimal sac fossa, elevating the lacrimal sac and exposing the lacrimal bone. A bony opening was made with the help of a trephine and was enlarged to 12-15 $\mathrm{mm}$ diameter with a nibbler, osteotomy size was measured with Castroviejo adjustable ophthalmic caliper superiorly from the medial palpebral ligament to inferior orbital rim margin inferiorly. Incision in the nasal mucosa was made followed by the reflection of lacrimal sac laterally, a Bowman's probe was passed through the canaliculus and a U-shaped flap was made of nasal mucosa and lacrimal sac. Anterior and posterior flaps of nasal mucosa and lacrimal sac were created. The flaps were anastomosed using 5-0 vicryl suture. Finally, the skin was closed with a continuous subcuticular 5-0 vicryl suture.

On the first postoperative day, removal of the nasal pack was done followed by the syringing of the lacrimal passage. Oral antibiotics were prescribed for 7 days and topical antibiotics for two weeks postoperatively. Nasal vasoconstrictor drops were given three times daily for two weeks in the postoperative period. Silastic tube was removed at 1 month postoperatively. 


\section{Statistical analysis}

Data were entered in MS Excel sheet 2007. Normality of the data was tested by Kolmogorov Smirnov test. Continuous data were presented as mean \pm standard deviation in case of parametric variable and median in nonparametric variable. Statistical analysis was performed using SPSS for windows, version 11.5 (SPSS Inc., Chicago,IL). Binary logistic regression models were used to investigate the association of the surgical outcome with various predicting variables. Variables included age, durations of symptoms, gender, use of silastic tube, flap anastomosis type and osteotomy size. All $p$ values were considered statistically significant when less than 0.05 .

\section{RESULTS}

The study included 105 patients in whom external DCR surgery was performed. The mean age was 22.04 years. The mean duration of symptoms was $25.23 \pm 21.12$ months (median, 24 months; range, 1-84 months). The mean osteotomy size was $12.52 \pm 2.73 \mathrm{~mm}$ (range, 7-20 mm). The baseline characteristics of the study sample are illustrated in table 1.

Table 1: Baseline characteristics of the patient $(n=105)$

\begin{tabular}{l|c}
\multicolumn{1}{c|}{ CharacteristicS } & Number (\%) \\
\hline Gender & $44(41.9 \%)$ \\
Male & $61(58.1 \%)$ \\
Female & \\
\hline Silastic tube & $38(36.2 \%)$ \\
Present & $67(63.8 \%)$ \\
Absent & \\
\hline Flap & $45(42.9 \%)$ \\
Anterior & $60(57.1 \%)$ \\
\hline Both & $12.52 \pm 2.73$
\end{tabular}

The highest number of patient with nasolacrimal duct obstruction was due to primary acquired nasolacrimal duct obstruction (PANDO) and the lowest number due to failed DCR (Figure 1).

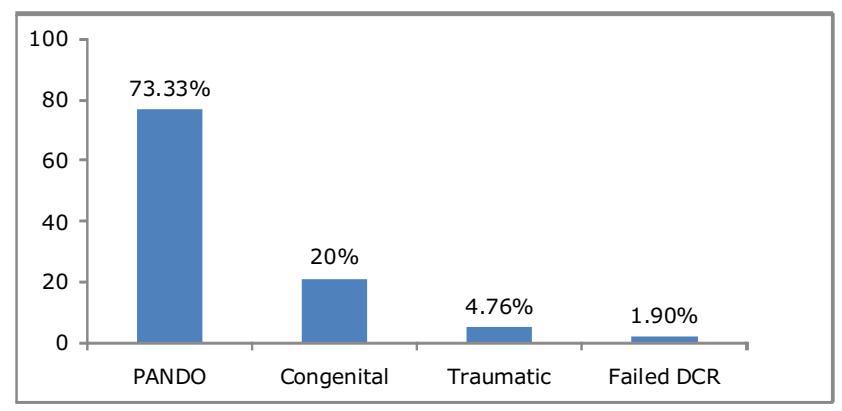

Figure 1: Distribution of external DCR surgery based on etiology $(n=105)$

Out of 105 patients, 82 patients had successful outcome of the surgery whereas 33 patients did not (Table 2).
Table 2: Descriptive analyses of independent variable based on surgical outcome (Success, Failed) ( $n=105)$

\begin{tabular}{|l|c|c|c|c|c|c|c|}
\hline \multirow{2}{*}{ Result } & \multicolumn{2}{|c|}{ Gender } & \multicolumn{2}{c|}{ Silastic tube } & \multicolumn{2}{c|}{ Flap } \\
\cline { 2 - 9 } & Male & Female & Present & Absent & Anterior & Both \\
\hline Success & 37 & 45 & 32 & 50 & 29 & 53 \\
\hline Failed & 7 & 16 & 6 & 17 & 16 & 7 \\
\hline
\end{tabular}

The binary logistic regression was conducted to predict the successful outcome of an external DCR surgery using age, duration of symptoms, gender, use of Silastic tube, type of flap surgery and osteotomy size. The Wald criterion demonstrated that only duration of symptoms $(p=0.02)$, osteotomy size $(p=0.005)$ made a significant contribution to the successful outcome of the surgery. Other factors were not a significant predictor (Table 3).

Table 3: Binary Logistic Regression Analysis between various factors with the outcome of the surgery (Success or Failure)

\begin{tabular}{llll} 
Variables & $\operatorname{Exp}(\mathbf{B})$ & $\mathbf{9 5 \%} \mathbf{C l}$ & $\boldsymbol{p}$-value \\
\hline Age (years) & 1.03 & $1.00,1.06$ & 0.051 \\
$\begin{array}{l}\text { Duration of symptoms } \\
\text { (months) }\end{array}$ & 0.95 & $0.92,0.99$ & 0.02 \\
Gender & & & \\
Silastic tube & 2.90 & $0.79,10.61$ & 0.10 \\
Flap & 1.87 & $0.50,6.96$ & 0.35 \\
Osteotomy size $(\mathrm{mm})$ & 2.74 & $0.75,9.97$ & 0.12 \\
& 0.65 & $0.49,0.88$ & 0.005
\end{tabular}

$\operatorname{Exp}(B)=$ Exponentiation of the $B$ coefficient (logistic coefficient)

$95 \% \mathrm{Cl}=95 \%$ confidence interval of the $\exp (\mathrm{B})$

\section{DISCUSSION}

The success rate in this study was $78.09 \%$, whereas in other studies it was found to be $94.7 \%$ and $90.4 \% .{ }^{14,15}$ The success rate of surgery in similar studies done in Nepal were $88.6 \%{ }^{10}$ and $89.2 \%$. ${ }^{7}$ Various literature reports the success rate to be between $80-99 \%{ }^{4 \cdot 19}$ The lower success rates in the present study may be attributed to multiple surgeons performing the surgery or a higher number of patients with congenital nasolacrimal duct obstruction when compared with other studies. Whereas, a study conducted by Limbu et al in Nepal reported no difference in the surgical outcome of dacryocystorhinostomy surgery between pediatric and adult age group. ${ }^{20}$

Among the commonly known etiologies of nasolacrimal duct obstruction, primary nasolacrimal duct obstruction was found in 77 (73.3\%), which is similar to other studies. ${ }^{11,13,14} 21$ $(20 \%)$ of the cases were of congenital nasolacrimal duct obstruction, traumatic etiology was found in 5 (4.76\%) and 2 (1.90\%) were due to failed DCR. Whereas a study of 169 consecutive DCR procedures from a US hospital contained only $5 \%$ due to presumed congenital nasolacrimal duct obstruction. ${ }^{13}$ 
The minimum and maximum age of presentation was 2 and 81 years respectively in our study which is similar to a study conducted by Kashkoli et al in which the age ranged from 3 to 84 years. ${ }^{14}$ The duration of symptoms ranged from 1 to 84 months which has significant association with the outcome of the surgery (Table 1, 2) p-value of 0.02.On the contrary, a similar study conducted by Kashkoli et al in 2003 did not show a significant association. ${ }^{14}$

Females accounted for $58.1 \%$ of the total patients included, which is comparable to other studies conducted in Nepal. ${ }^{10}$ The study done by Kashkoli et al in a different geographic area reported the female to be $66.7 \%$ of the total patients. ${ }^{14}$ No significant association between the gender and the surgical outcome could be established in our study.

Various literature show the osteotomy size to be $18.2 \mathrm{~mm}$ and $11.84 \mathrm{~mm} .^{18,19}$ The mean osteotomy size was $12.52 \mathrm{~mm}$ in our study. It is widely accepted that larger osteotomy size yields better results. In this study, the osteotomy size has significant association with the outcome of the surgery (Table 3) with a p-value of 0.005 which is similar to other studies that reported larger the osteotomy size, better is the success rate of DCR surgery. ${ }^{18}$ On the contrary, Simon et al reported that the osteotomy size does not influence the outcome of the surgery. ${ }^{21}$ It is widely believed that the final outcome of the surgery not only depends upon the osteotomy size intraoperatively but also the size of the ostium postoperatively as the ostium can contract over a period of time. So, an endoscopic approach for the measurement of the ostium size should be done to further support our study.

The use of silicone tube during external DCR in cases of primary nasolacrimal duct obstruction (NLDO), canalicular obstruction or in revision surgeries is still controversial. ${ }^{22} \mathrm{~A}$ meta-analysis conducted by Feng et al showed no significant difference between the success rate of DCR surgery with or without the use of silicone tube. ${ }^{23}$ On the contrary, a study conducted by Veira and Xavier reported successful outcome

\section{REFERENCE}

1. Harish V, Benger RS. Origins of lacrimal surgery, and evolution of dacryocystorhinostomy to the present. Clinical \& experimental ophthalmology. 2014 Apr 1;42(3):284-7.

2. Hartikainen J, Antila J, Varpula M, Puukka P, Seppä H, Grénman R. Prospective randomized comparison of endonasal endoscopic dacryocystorhinostomy and external dacryocystorhinostomy. The Laryngoscope. 1998 Dec 1;108(12):1861-6.

3. Ibrahim HA, Batterbury M, Banhegyi G, McGalliard J. Endonasal laser dacryocystorhinostomy and external dacryocystorhinostomy outcome profile in a general ophthalmic service unit: a comparative retrospective study. Ophthalmic Surgery, Lasers and Imaging Retina. 2001 May 1;32(3):220-7.

4. Watkins LM, Janfaza P, Rubin PA. The evolution of endonasal dacryocystorhinostomy. Survey of ophthalmology. 2003 Feb 28;48(1):73-84. with its use. ${ }^{24}$ The use of silicone tube intubation had no significant association with the outcome in this study.

It is widely considered that the anastomosis of both the anterior and posterior flap increases the chance of successful surgical outcome. ${ }^{25}$ On the contrary to this assumption, there was no significant association between type of flap anastomosis with the outcome of the surgery in our study, which is similar to the study conducted by Turkcu, Elwan and Kacaniku. ${ }^{26,27,28}$ While performing external dacryocystorhinostomy surgery, anastomosis of both the flap is technically difficult and time consuming compared to the anastomosis of anterior flap only. Review of literature doesn't show significance difference between the types of flap anastomosis too. So, use of only anterior flap anastomosis will have good outcome in external dacryocystorhinostomy surgery.

\section{CONCLUSION}

Our study yielded high success rate in patients with shorter duration of watering of eyes and larger osteotomy size during surgery. The use of silastic tube and type of flap did not affect the outcome of the surgery.

\section{RECOMMENDATIONS}

A prospective longitudinal study to evaluate the factors affecting the outcome of the dacryocystorhinostomy surgery is recommended.

\section{LIMITATION OF THE STUDY}

There were few limitations of the study. Firstly, secondary data from the medical record file were evaluated which may not be accurate or reliable. Secondly, the cross-sectional study design could not evaluate the outcome of the surgery over a period of time.

\section{ACKNOWLEDGMENT}

We would like to thank Department of Ophthalmology, BPKIHS for their constant support to conduct this study.

\section{CONFLICT OF INTEREST}

We declare no conflict of interest.

5. McDonogh M, Meiring JH. Endoscopic transnasal dacryocystorhinostomy. The Journal of Laryngology \& Otology. 1989 Jun 1;103(06):585-7.

6. Massaro BM, Gonnering RS, Harris GJ. Endonasal laser dacryocystorhinostomy: a new approach to nasolacrimal duct obstruction. Archives of ophthalmology. 1990 Aug 1;108(8):1172-6.

7. Katuwal S, Aujla JS, Limbu B, Saiju R, Ruit S. External dacryocystorhinostomy: do we really need to repair the posterior flap ?. Orbit. 2013 Apr 1;32(2):102-6.

8. Yakopson VS, Flanagan JC, Ahn D, Luo BP. Dacryocystorhinostomy: History, evolution and future directions. Saudi Journal of Ophthalmology. 2011 Mar 31;25(1):37-49.

9. Ibrahim BB, Serin D. Silicone Intubation Indications in External Dacryocystorhinostomy. Medical Hypothesis, Discovery \& Innovation Ophthalmology Journal. $2014 \operatorname{Jan}$ 1;3(4):101. 
10. Badhu B, Dulal S, Kumar S, Thakur SK, Sood A, Das H. Epidemiology of chronic dacryocystitis and success rate of external dacryocystorhinostomy in Nepal. Orbit. 2005 Jan 1;24(2):79-82.

11. O'Donnell B, Shah R. Dacryocystorhinostomy for epiphora in the presence of a patent lacrimal system. Clinical \& experimental ophthalmology. 2001 Feb 1;29(1):27-9.

12. Hurwitz JJ, Rutherford S. Computerized survey of lacrimal surgery patients. Ophthalmology. 1986 Jan 1;93(1):14-9.

13. Tarbet KJ, Custer PL. External dacryocystorhinostomy: surgical success, patient satisfaction, and economic cost. Ophthalmology. 1995 Jul 1;102(7):1065-70.

14. Kashkouli MB, Parvaresh MM, Modarreszadeh M, Hashemi M, Beigi $B$. Factors affecting the success of external dacryocystorhinostomy. Orbit. 2003 Jan 1;22(4):247-55.

15. Struck HG, Weidlich R. Indications and prognosis of dacryocystorhinostomy in childhood. A clinical study 1970-2000. Der Ophthalmologe: Zeitschrift der Deutschen Ophthalmologischen Gesellschaft. 2001 Jun;98(6):560-3.

16. Huang J, Malek J, Chin D, Snidvongs K, Wilcsek G, Tumuluri K, Sacks R, Harvey RJ. Systematic review and meta-analysis on outcomes for endoscopic versus external dacryocystorhinostomy. Orbit. 2014 Apr 1;33(2):81-90.

17. Shun-Shin GA, Thurairajan G. External dacryocystorhinostomy-an end of an era?. British journal of ophthalmology. 1997 Sep 1;81(9):716-7.

18. Warren JF, Seiff SR, Kavanagh MC. Long-term results of external dacryocystorhinostomy. Ophthalmic Surgery, Lasers and Imaging Retina. 2005 Nov 1;36(6):446-50.

19. GJ, Brown C, McNab AA. Larger osteotomies result in larger ostia in external dacryocystorhinostomies. Archives of facial plastic surgery. $2012 \operatorname{Mar} 1 ; 14(2): 127-31$.
20. Limbu B, Katwal S, Lim NS, Faierman ML, Gushchin AG, Saiju R. Comparing outcomes of pediatric and adult external dacryocystorhinostomy in Nepal: Is age a prognostic factor?. Orbit. 2017 Apr 2:1-6.

21. Simon GJ, Brown C, McNab AA. Larger osteotomies result in larger ostia in external dacryocystorhinostomies. Archives of facial plastic surgery. 2012 Mar 1;14(2):127-31.

22. Linberg JV, Anderson RL, Bumsted RM, Barreras R. Study of intranasal ostium external dacryocystorhinostomy. Archives of Ophthalmology. 1982 Nov 1;100(11):1758-62.

23. Feng $Y F$, Cai JQ, Zhang JY, Han XH. A meta-analysis of primary dacryocystorhinostomy with and without silicone intubation. Canadian Journal of Ophthalmology/Journal Canadien d'Ophtalmologie. 2011 Dec 31;46(6):521-7.

24. Vieira GS, Xavier ME. Results and complications of bicanalicular intubation in external dacryocystorhinostomy. Arquivos brasileiros de oftalmologia. 2008 Aug;71(4):529-33.

25. Yazici B, Yazici Z. Final nasolacrimal ostium after external dacryocystorhinostomy. Archives of Ophthalmology. 2003 Jan 1;121(1):76-80.

26. Türkcü $F M$, Öner $V$, Taş $M$, Alakuş $F$, İşcan $Y$. Anastomosis of both posterior and ante rior flaps or only anterior flaps in external dacryocystorhinostomy. Orbit. 2012 Dec 1;31(6):383-5.

27. Elwan S. A randomized study comparing DCR with and without excision of the posterior mucosal flap. Orbit. 2003 Jan 1;22(1):7-13.

28. Kacaniku G, Begolli I. External dacryocystorhinostomy with and without suturing the posterior mucosal flaps. Medical Archives. 2014 Jan 1;68(1):54. 